\title{
Commentary
}

\section{How Georgia may learn from changes in principal support and supervision internationally}

The role of a modern school principal, with the focus on becoming an instructional and learning leader for school society, rather than being only a building manager, is changed from the past in myriad countries. New practices and job requirements lead to the issues of principal preparedness for the role, challenges in providing effective support to principals and changes in the form of principal supervision. An increased role in this process is played by middle-tier agencies. Their closer involvement in the process of principal support and supervision requires them to redesign their traditional methods of supervision and to depart from prior practices of controlling principals to supporting and coaching them. The papers in this volume of $J E A$ provide a good overview of how different countries are approaching and grappling with the abovementioned issues.

Georgia is a country situated in the South Caucasus bordering the Black Sea, Turkey, Russia, Azerbaijan and Armenia. Its ancient history, starting since the fourth century BC, as well as its geographic location on the border of two continents, Europe and Asia, has resulted in both western and eastern cultures influencing the creation and development of Georgian civilization. Georgia was absorbed into the Russian Empire in the nineteenth century. It existed for three years (1918-1921) as an independent democratic republic, followed by the Russian Socialist revolution when Georgia was forcibly incorporated into the USSR. After the Soviet Union was dissolved in 1991, the country regained its independence.

Despite the fact that Georgia is a small country $\left(69,700 \mathrm{~km}^{2}\right)$, it has varied landscapes and urban and rural areas with a population of diverse ethnic, religious and cultural backgrounds. A total of 2,085 public schools in the country differ in size and range from very small schools in rural, mountainous villages with $2-3$ students of different ages to large schools accommodating 2,000 or more student in the cities. There are also schools with students from ethnic minorities, as well as from internally displaced families as a result of the Russian occupation of 20 percent of Georgian territories.

Alongside political, economic and social reforms, intensive educational reforms have been taking place in Georgia since 2004 as the nation has broken away from the practices of highly centralized educational systems that existed in the countries of the former Soviet Union. Despite frequent changes in the Office of the Ministry of Education (now the Ministry of Education, Science, Culture and Sport) and decisions by leadership causing the processes to flow from centralization to decentralization, and vice versa, at different periods, many steps and reforms have been made forward in the creation of a new national curricula, upgrade of textbooks, teacher retraining, school governance and principal training, new use of technologies in the educational process and other small- or large-scale reforms. The reforms aim for learning processes to become more student centered and relevant to the requirements of the twenty-first century workforce.

Yet, much work remains to be conducted to improve both education policy and practices in Georgia. According to students' performance on benchmarking assessments (TIMSS, PIRLS, PISA), student outcomes have been slowly increasing, while overall performance is still low. On the 2015 PISA, Georgian students' average score was 411, below the OECD average (493), with Singapore leading the chart with a score of 556 (OECD, 2018). At the same time, disparities exist between students' performance in urban and rural schools, public and private schools, and Georgian and ethnic minority schools. According to TIMSS 
2015 results, the fourth grade students showing low and very low levels of performance were mostly from rural areas (68 percent) (TIMSS, 2015).

In light of this background, the school principal's role is becoming essential and needs to be closely focused on improving teaching and learning processes in schools, on assisting and motivating teachers to raise their professional qualifications and on acquiring and using new, student-centered methods of instruction in parallel with providing equal opportunities for students and solving school-specific managerial problems.

School autonomy has been one of the main topics of discussion in school reform. On the one hand, steps were made to democratize school governance by creating school governing boards to which the school principal is accountable at each school. School governing board members work on a voluntary basis consisting of a group of representatives of teachers, parents, community members and local government officials. As practice shows, most of the school boards are not actively involved in the work of the school, though they still provide a mechanism for hearing school stakeholder voices in defining school mission and strategy and allocation of finances (EPPM Report, 2014). On the other hand, school principals are under the Ministry's close control through Educational Resource Centers (ERCs), School Boards and the Ministry's Department of General Inspection, which is eligible to initiate school inspections in managing administrative issues and proper usage of financial resources. Despite the many controllers of school principal activities, there are few supportive mechanisms in place to assist school principals in tackling school-specific issues that are either instructional or managerial in nature.

The following commentary will examine the findings from the studies included in this special issue under three topic areas, while making parallels with Georgia's experience. This paper will also identify the findings that may be used as lessons learned and best practices from the conducted reforms, particularly as it applies to the Georgian context:

- changed role of school principals and their supervisors;

- altered approaches to supervision and professional development of school principals; and

- increased role of a middle tier in the professional development of principals.

\section{Changed role of school principals and their supervisors}

One of the main topics covered in the articles was the significant change in the roles and responsibilities of school principals in order to become instructional leaders and adequately lead the instructional improvement process in the school setting. This change was followed by the necessity to reshape the roles and responsibilities of principal supervisors at the district offices as well. As it is noted in the article "Establishing productive principal/ principal supervisor partnerships for instructional leadership" (Thessin, 2019) in the USA, district supervisors were formerly engaged in business and compliance activities; now, "district office supervisors started instead to provide intensive, job-embedded coaching to principals to strengthen their instructional leadership" (Honig, 2012; Corcoran et al., 2013). This means that they became "more engaged in coaching, mentoring and partnering with the specific goal of improving student achievement" (Browne-Ferrigno and Allen, 2006; Clarke and Wildy, 2011; Johnson and Chrispeels, 2010; Leithwood, 2010). The same processes are reported as taking place in other localities of the USA as well as in Canada, Australia and Scotland (Leithwood et al., 2019; Wilkinson et al., 2019; Honig and Rainey, 2019; Chapman, 2019). The changing role of principal supervision has triggered various approaches and efforts to achieving success. The empirical studies identified the conditions that have helped and hindered these processes. These findings can be used very effectively to inform countries where this reform is underway, as in Georgia. 
JEA

57,5

\section{What can be learned from the experience?}

Responding to the new requirements to implement student-centered classrooms and focus on students' improved learning, perception of the role of a public school principal also started to change in Georgia in 2013. Traditionally, in Georgia, as in many of the countries referenced in this special issue, school principals have been viewed more as school managers than as instructional leaders. They have had little responsibility for the instructional process, which was perceived to be teachers' area of responsibility. For many years, entry into the school principal position in Georgia did not require teaching experience as it is required in many other countries. Not until 2018 was a requirement introduced for administrative applicants to have at least one year of teaching experience in order to become a school principal.

In Fall 2015, Georgia started implementing a reform aimed at teacher professional development enhancement by introducing a teacher professional development and career advancement scheme. The scheme instituted distribution of about 67,000 teachers along four career steps, starting from the practitioner teacher, followed by senior teacher, lead teacher and mentor teacher statuses. One of the components required for teacher advancement on the career ladder was the evaluation received from a school-based evaluation committee headed by the school principal.

As a result of this new career ladder with specific evaluation requirements, the school principal's role as an instructional leader increased. Formerly, school principals were administrators who were rarely seen in the classroom and were not directly involved in teacher supervision. In the Soviet period, teacher professional development training centers were engaged in such activities and considered to be competent to oversee and advise how teachers were carrying out teaching and learning processes in the classroom. Now, in order to evaluate teachers, school principals must be well aware of modern teaching approaches and methods used by teachers, be competent in school curricula and design teachers' professional development. Essentially, new expectations for the principal suddenly required Georgian principals to become instructional leaders overnight. For school principals not having prior teaching experience, these new requirements were a double challenge. However, in January 2019, the teacher professional development and career advancement scheme was substantially altered by the decision of the new Ministry of Education, Science, Culture and Sport, leaving the school and general society with more questions how and who will be responsible for teacher evaluation and professional development. The preliminary thoughts and prognosis are that schools and school administration will be charged with more responsibilities in this respect.

In light of these new requirements, school principals in Georgia will need to continue to change the nature of their work to become instructional leaders, allocating more time to visiting classrooms for evaluating, assisting and coaching teachers, and also serving as learning leaders who build learning organizations and create learning opportunities for the whole school community.

\section{Approaches to supervision and professional development of school principals}

The findings of the empirical articles in this special issue also demonstrated the importance of utilizing a variety of approaches for supervision and professional development of school principals. The findings prove that the statement "one-size does not fit all" is applicable to principal professional development as well. Wilkinson et al.'s (2019) study drew on the theory of practice architectures that rejects "a one-size fits all" approach to educational change. The two case studies conducted in Australia demonstrated how reforms implemented by local districts can take different shapes when tailored to local schools' contexts (Wilkinson et al., 2019). This approach is especially valuable when the reform is carried out in a country having a diversity of school cultures, philosophies, communities, geographical locations, school sizes, and ethical and religious backgrounds. The findings 
point to the need for greater flexibility of district roles and responses to schools and a conceptualization of change at the district level that recognizes "complexity" and "nonlinearity" (Leithwood, 2010).

Thessin (2019) reported on the form and process of principals' professional learning experiences that result in robust changes in principal practice. She also identified the antecedents and contributions to successful coach/coachee partnerships, such as skillfulness and credibility of the coach establishment of an atmosphere of support and collegiality with the whole school team, principal motivation, and engagement in joint work and the feeling of joint commitment to and ownership of the work. From the principal side, having the ability to reflect on one's own practice and to be a self-regulated learner, as well as the motivation to succeed, was identified as a very important factor in successful partnerships (Thessin, 2019).

\section{What can be learned from the experience?}

The above-mentioned findings can be successfully adapted and taken into account in the context of Georgia while rethinking and planning further steps in the nation's own principal professional development reforms.

In 2016-2018, to promote economic growth and reduction of poverty in Georgia, and as funded by the US Millennium Challenge Corporation and Millennium Challenge Account-Georgia, National Center for Teacher Professional Development implemented the nationwide teacher and principal retraining project entitled "Training Educators for Excellence (TEE)." One direction of the project, the "Leadership Academy," aimed to train public school principals in new approaches required for leading the twenty-first century schools. The project was implemented in 2016-2018. Being on the leadership team of this project from the start, I was closely involved in all the stages of project implementation, including designing, planning, implementation and evaluation. In addition to closely supervising the content of the project, I led the managerial aspects of the project involving the coordination of field experts, communicating with donor organizations, foreign experts, Ministry of Education and Science representatives, gender experts and other beneficiaries. A comprehensive "Leadership Academy" training course was created that consisted of three series of trainings encompassing 160 contact hours over three years.

All public school principals of Georgia were invited to participate in the Leadership Academy. About 1,900 principals get engaged in the Leadership Academy trainings. Among them were also about 200 principals from the areas of the country populated with ethnic minorities. For them, the 11 training modules originally created in the Georgian language for Georgian speaking principals were translated and conducted in their native languages of Azerbaijani, Armenian and Russian. These training modules encompassed a variety of topics, such as instructional leadership, shared leadership and adult learning, mentoring of instruction, leadership and supervision, development of learning communities, closing the gap and equity issues, and supporting student autonomy through assessment and technology use, as well as others. The modules broadly aimed to provide Georgian principals with the theory and skills to actively act as instructional leaders, understand curricula requirements, conduct action research and base school improvement decisions on data-driven analysis. Leadership Academy trainings were conducted very successfully, as judged by principals who provided favorable feedback (Table I). 
JEA

57,5

As there is always a risk that in most cases the learning taking place at the trainings do not find continuation and further implementation at schools, the trainings were followed up by quarterly meetings for principals within their municipalities, as organized by the project. At quarterly meetings, principals shared how they applied their learning and made changes at their schools after the trainings. This work resonates with the findings of the Scandinavian cases, where peer instruction and sharing of best practices along with "individual and collective reflecting practices among the principals" led to successful ongoing professional development and to learning transfer to schools (Aas and Paulsen, 2019).

To look back at the conducted work and draw on the research findings in this special issue, Georgia's Leadership Trainings were still a top down and "one-size fits all" approach to principal professional development. Such a large-scale training effort in a limited time period could not be tailored to the specifics of each school. During the implementation period, the need for a more targeted approach became evident. Principals were exposed to many new ideas and approaches at the trainings, but they needed time to digest new information, rethink existing practices and transfer new approaches to their schools. According to Goff "it is unlikely that providing school leaders with feedback received from the trainers alone will induce behavioral change. Other systems and supports - such as leadership coaching - are needed to help them make sense of the new approaches, data and translate data into actionable behaviors" (Goff et al., 2014). After completion of the Leadership Academy training project in 2019, further steps should be taken to assist principals and motivate them to apply the new knowledge at their schools, make behavioral changes and start acting as instructional leaders. Creation of a system of continuous professional learning support will be needed for the sustainability of the project results. Based on findings from the articles in this issue, the principals will benefit from job-embedded, school-based consulting and coaching opportunities to solve the school-specific instructional challenges they face and start introducing reforms in their schools (Thessin, 2019; Chapman, 2019).

In this respect, continuation of principal professional development in Georgia will be essential in some form. This might be done with the introduction of a variety of mechanisms for assisting principals, ranging from creating a hot line consultancy for the principals when they need urgent help on site to the introduction of a full-fledged system of principal coaching. A pool of 106 retrained and experienced TEE project principal trainers, who were principals themselves or have years of experience as principal mentors, could be a good resource to build on for creating a system of principal coaching and support in Georgia. However, it should be taken into account that the introduction of a full-fledged coaching system may be costly and encounter challenges in becoming an effective tool in practice. According to the research findings, the coaching process should be well planned and the coaches carefully selected. They should develop partnerships on trust and empathy (Thessin, 2019). On the other hand, it is important that the principals involved in this process have the ability and willingness to reflect on their own activities and engage as learners. Fulfilling these prerequisites may lead to successful results.

\section{Role of a middle tier: Educational Resource Centers in professional development of principals}

Almost all of the articles in the special issue touch upon the importance of strengthening the role of middle-tier agencies, or school district central offices, in principal professional development. It is evident that district offices are redesigning their traditional roles and reorienting/modifying the functions and roles of supervisors in supporting instructional leadership practice at school levels in order to improve students' learning outcomes. Middle-tier agencies are perceived as playing indirect but crucial roles in improving 
student outcomes (Wilkinson et al., 2019). This leads to further questions regarding how districts themselves are preparing to fulfill the new role of assisting principals in becoming instructional leaders? Do middle-tier agencies or school district central offices have sufficient qualifications to do so, and will their current workload allow them to be effective coaches?

The article's findings from the research conducted in Canada (Leithwood et al., 2019) show that not all the practices of school districts show correlation with improvement in student achievement. Among other factors, teacher trust, collective teacher efficacy, and safe and orderly environments should be taken into account when tasking the regional districts with new responsibilities. Under the conditions of limited resources and small budgets, districts should focus on the areas of principal training that are in direct relation with improvement of student learning outcomes.

\section{What can be learned from the experience?}

In Georgia, school principals are monitored and controlled by various agencies such as school boards, ERCs, the Internal Audit Department of the Ministry, National Center for Educational Quality Enhancement, and other governmental agencies; it is not clearly defined which governmental agency's responsibility it is to supervise, mentor or coach school principals. Furthermore, there is no entity clearly responsible for providing assistance to principals in acquiring knowledge for their new roles as instructional leaders.

Overall, it is ambiguous which agency is responsible to provide a system of professional learning support to principals: ERCs, Teacher Professional Development Center (TPDC), The National Center for Educational Quality Enhancement or The National Assessment and Examinations Center. Despite the fact that a number of legal entities have in their mandate to provide principals with professional development, during 2013-2015, the provided assistance was sporadic and irregular. Only the principals who had expressed an interest had an opportunity to participate in the trainings periodically organized by TPDC, the international organizations or local NGOs.

Also, Georgian universities are weakly engaged in the process of school principal professional development. There are few special programs, courses and partnerships focused on assisting school principals with their professional development needs. As one example of a university - school partnership, Ilia State University's Education Administration Program cooperates with a small number of schools and master's level students who are conducting action research projects at schools. However, the geography of partnerships is limited and takes place mostly in Georgia's capital, Tbilisi. Very few regional universities are engaged in intensive partnerships with schools.

There is a clear need to increase the responsibility of middle-tier agencies of the Ministry in principal professional development. The Georgian Ministry of Education, Science, Culture and Sport has 68 regional representations almost in each municipality, known as ERCs. These centers can be viewed as a "middle tier." They are most aware of the specific needs of the schools in their regions and the territories in their jurisdiction. At present, by law, ERCs are responsible to work with a various number of schools, ranging from 7 to 64 . On average, 25-30 schools are supported by each ERC.

In assuming this new role, however, ERCs face a number of barriers. First, the ERCs are overloaded with multiple functions and tasks that they are receiving from the Ministry. A big part of the ERCs' work is related to collecting data on general educational institutions: material-technical, human and financial resources, the processing of data and double checking its accuracy at the relevant organization on site. They also participate in public schools' property management in accordance with legislation, register applicants for enrolling at professional educational programs; support conducting national examinations; support organization of local and international assessment process; and register students 
JEA

57,5

enrolled in accredited higher educational organizations eligible for state learning grants, among many other responsibilities not directly related to the learning improvement process. ERCs oversee that public schools follow national curricula, monitor educational processes and environment at school, evaluate and send the recommendations to the public schools and the Ministry. The ERCs also oversee the process led by the school governing board to select school principals from the proposed candidate list provided by the Ministry.

As we see, the ERCs are quite overloaded with different tasks and simply adding the responsibility of coaching principals to all of these tasks would not be successful. At the same time, not all of the ERC heads or staff members may be qualified to become coaches as qualifications differ from region to region. It will be necessary to attract/prepare new relevant personnel for filling the ERC director and staff positions with individuals ready to be coaches for principals in instructional leadership who can "take a teaching-and-learning stance to their work with principals" (Chapman, 2019). As Chapman (2019) indicates, "recasting the principal supervisor job description could have been a lever of change" while selecting principal supervisors. Also, Thessin (2019) suggest, that principal supervisor candidates tasked with coaching responsibilities should be screened carefully and selected according to their demonstrated capacity for leading their own learning, and know how to create conditions that support them in exercising such leadership.

If coaching responsibilities are added to ERCs, their functions and workload must be re-conceptualized. Their obligations, responsibilities and job descriptions should be reviewed and their time be freed up for focusing on coaching tasks. While changing their role, the focus should be on those strategies that are most likely to affect student achievement. Many of their current tasks, as detailed previously, are not connected with teaching and learning processes and are more of a technical and compliance nature, rather than consulting or coaching. The same struggles were identified in US districts and in Australian schools as the roles of principal supervisors changed from one of a supervisor to a coach (Thessin, 2019; Wilkinson et al., 2019). While focusing attention on reconceptualizing and redesigning job responsibilities of principal supervisors at districts, it should be taken into account which factors of district work have more effect on student achievements. The findings in one of the articles (Leithwood et al., 2019) suggest that "results indicated that district effects on student achievement were mediated by three of the four categories of mediators but especially by the same three specific mediators - teacher trust, collective teacher efficacy, and safe and orderly environments" (Leithwood et al., 2019).

Findings from the empirical articles demonstrate that professional learning systems for principals should be fit to individual school and school principals' needs and be job-embedded. ERCs seem to be the agencies that most closely work with schools and are most aware of their specific needs. They can also be perceived as supporters of peer learning and share experiences across municipality schools while continuing the organization of principals' quarterly meetings initiated by the TEE project. In order to ensure that individual principals' needs are better met at a local level, more decentralization of power to ERCs, and strengthening the ERCs with further resources, may be beneficial. Empowering the middle tier to become the main supporter for principals, especially in identifying their professional development needs and forms, will make it possible to target professional development to local needs and provide timely and regular support to principals.

\section{Conclusion}

In conclusion, Georgia can well use the findings of the empirical articles in this issue in building an effective and sustainable educational system that will support school principals in effectively assuming their new roles as instructional and learning leaders. The system will be more effective if it is not a top down and "systemic," "one-size fits all" approach, but one that is adaptable and has flexibility to be tailored to each school's needs, 
cultures and philosophies. Building of such a system seems to be more feasible through strengthening the capacities of, and rearranging the functions and duties of, the middle-tier agencies, such as the ERCs and their personnel. ERCs are closest to understanding each municipality's school needs in their regions. As to the form of assistance to be provided to the principals, an important component of any effective professional development system includes direct support to principals while taking into account the identified antecedents for forming effective coach/coachee partnerships in order to gain the most from the resources dedicated to educational reforms. Potential results from scaling up university-ERC-school partnerships also provide great potential for further growth. The combination of these approaches, and setting clear strategies for principal professional development for the future, may lead to successful results and increased achievement for students in Georgia's schools.

\section{Maya Bitsadze School of Business, Technology and Education, Ilia State University, Tbilisi, Georgia}

\section{References}

Aas, M. and Paulsen, J.M. (2019), "National strategy for supporting school principal's instructional leadership: a Scandinavian approach", Journal of Educational Administration, Vol. 57 No. 5, pp. 540-553.

Browne-Ferrigno, T. and Allen, L.W. (2006), "Preparing principals for high-need rural schools: a central office perspective about collaborative efforts to transform school leadership", Journal of Research in Rural Education, Vol. 21 No. 1, pp. 1-16.

Chapman, C. (2019), "From hierarchies to networks: possibilities and pitfalls for educational reform of the middle tier", Journal of Educational Administration, Vol. 57 No. 5, pp. 554-570.

Clarke, S. and Wildy, H. (2011), "Improving the small rural or remote school: the role of the district", Australian Journal of Education, Vol. 55 No. 1, pp. 24-36.

Corcoran, A., Casserly, M., Price-Baugh, R., Walston, D., Hall, R. and Simon, C. (2013), "Rethinking leadership: the changing role of principal supervisors", available at: www.wallacefoundation. org/knowledge-center/Documents/Rethinking-Leadership-The-Changing-Role-of-PrincipalSupervisors.pdf (accessed November 8, 2018).

EPPM Report (2014), "School governing boards in Georgia”, available at: https://drive.google.com/file/ d/0B9RC0lzxlY4ZSFROOC1nbEotZEE/view (accessed January 10, 2019).

Goff, P., Guthrie, J.E., Goldring, E. and Bickman, L. (2014), "Changing principals' leadership through feedback and coaching”, Journal of Educational Administration, Vol. 52 No. 5, pp. 682-704.

Honig, M.I. (2012), "District central office leadership as teaching: how central office administrators support principals' development as instructional leaders", Educational Administration Quarterly, Vol. 48 No. 4, pp. 733-774.

Honig, M.I. and Rainey, L.R. (2019), "Supporting principal supervisors: what really matters?”, Journal of Educational Administration, Vol. 57 No. 5, pp. 445-462.

Johnson, P. and Chrispeels, J. (2010), "Linking the central office and its schools for reform”, Educational Administration Quarterly, Vol. 46 No. 5, pp. 738-775.

Leithwood, K. (2010), "Characteristics of school districts that are exceptionally effective in closing the achievement gap", Leadership and Policy in Schools, Vol. 9 No. 3, pp. 245-291.

Leithwood, K., Sun, J. and McCullough, C. (2019), "How school districts influence student achievement", Journal of Educational Administration, Vol. 57 No. 5, pp. 519-539.

OECD (2018), "PISA 2015 results in focus", available at: www.oecd.org/pisa/pisa-2015-results-in-focus. pdf (accessed November 21, 2018).

Thessin, R.A. (2019), "Establishing productive principal/principal supervisor partnerships for instructional leadership”, Journal of Educational Administration, Vol. 57 No. 5, pp. 463-483. 
TIMSS (2015), available at: http://timssandpirls.bc.edu/timss2015/international-results/downloadcenter/ (accessed December 27, 2018).

Wilkinson, J., Edwards-Groves, C., Grootenboer, P. and Kemmis, S. (2019), "District offices fostering educational change through instructional leadership practices in Australian Catholic secondary schools", Journal of Educational Administration, Vol. 57 No. 5, pp. 501-518.

\section{Further reading}

Fullan, M. (2014), The Principal: Three Keys to Maximizing Impact, Jossey Bass \&Wiley Brand.

Georgian Government Order No. 35 (2017), "Teacher professional activity commencing, professional development and career advancement scheme", available at: http:/tpdc.gov.ge/uploads/pdf documents/new1000.pdf (accessed November 21, 2018).

Georgian Law on General Education (2017), available at: https:/matsne.gov.ge/en/document/ download/29248/56/en/pdf (accessed November 8, 2018).

Georgian Minister of Education and Science (2017), "Order \# 47/n on ERC activities", (accessed November 8, 2018).

Rigby, J., Donaldson Walsh, E., Boten, S., Deno, A., Harrison, M.S., Merrell, R., Pritchett, S. and Seaman, S. (2019), "A view from the field: the process of improving equitable systems leadership", Journal of Educational Administration, Vol. 57 No. 5, pp. 484-500. 